Article

\title{
Rethinking the Identification of Urban Centers from the Perspective of Function Distribution: A Framework Based on Point-of-Interest Data
}

\author{
$\mathrm{Lu} \mathrm{Yu}{ }^{1}$, Tao $\mathrm{Yu}^{1, *}$, Yongxiang $\mathrm{Wu}^{1}$ and Guangdong $\mathrm{Wu}^{2}$ \\ 1 School of Civil Engineering, Harbin Institute of Technology, Harbin 150090, China; yulu@hit.edu.cn (L.Y.); \\ wuyx@hope.hit.edu.cn (Y.W.) \\ 2 School of Public Affairs, Chongqing University, Chongqing 400044, China; gd198410@cqu.edu.cn \\ * Correspondence: yutao2018@hit.edu.cn or yutao2012tjdx@163.com
}

Received: 31 January 2020; Accepted: 18 February 2020; Published: 19 February 2020

\begin{abstract}
Urban spatial structure has a significant impact on the sustainable development of cities. An important step of urban spatial structure analysis is the identification of urban centers. From the perspective of urban function distribution, this study developed a theoretical framework of three layers for urban center identification. In the first layer, point-of-interest data were collected from geospatial databases and utilized to capture the spatial distribution of urban functions. In the second layer, the density-based spatial clustering of application with noise (DBSCAN) algorithm was employed to group points of interest into urban centers according to their inter-distances and urban functions. In the third layer, the spatial distribution of the identified urban centers was visualized by the ArcGIS platform. This framework was applied in the urban center analysis of Beijing. The results showed that Beijing is in the process of transitioning from monocentric to polycentric with urban functions distributed unevenly throughout the city. To facilitate this transition, strategies such as the construction of super-large communities, the development of branch campuses and higher-education parks, and the enhancement of modern culture industries should be considered for the 11 new towns of Beijing.
\end{abstract}

Keywords: Beijing; density-based spatial clustering of application with noise; point of interest; urban center; urban function; urban spatial structure

\section{Introduction}

Urbanization is a socio-spatial process, which is directly related to the expansion of urban areas and the growth of urban population [1]. Developed countries such as America, Japan, and the UK have already completed their urbanization processes. In recent decades, developing countries such as China are still striving for urbanization. In its Five-Year Plans (the most important economic development policy of China), China has highlighted the new-type urbanization as an important goal for its future development. As a result, the urbanization rate of China increased significantly from $13.26 \%$ in 1953 to $59.58 \%$ in 2018 [2], which has resulted in a number of mega cities such as Beijing, Shanghai, Guangzhou, and Shenzhen. According to the 2018 global city evaluation by the Globalization and World Cities Study Group and Network, China now has six global first-tier cities (i.e., alpha-level cities). Despite the huge benefits offered by the rapid urbanization, it also exerts enormous pressure on the sustainable development of China's cities. Specifically, the supply of urban infrastructure and public services cannot meet the increasing demand incurred by the large number of urban dwellers, which have incurred a series of urban sustainability problems such as traffic congestion, air pollution, and uneven resource allocation [3]. Due to unbalanced urban development, urban function resources typically 
concentrate in the center areas of cities, resulting in unreasonable population densities of urban core areas $[4,5]$. To cope with these sustainability problems, scientific urban planning and management methods are critical for Chinese planners and government officials.

Urban spatial structure (USS) analysis plays a significant role in urban planning and management [6]. It helps practitioners to capture a city's overall conditions and design effective strategies for addressing urban sustainability problems $[7,8]$. Studies have analyzed spatial structure in different cities, focusing primarily on linkages between urban morphology and function distribution [9]. In such studies, urban center (UC) identification has been highlighted as an important step for USS analyses $[10,11]$ because UCs serve as critical nodes of an urban system, continuously supporting the operation of urban functions. Thus, effective methods for mapping the distribution of UCs factor centrally in USS analyses, especially in analyses of polycentric cities [7,12].

Due to the rapidity of urbanization, more than half of the world's population now lives in urban areas [13]; this situation has given rise to megacities with multiple UCs [10,14]. For such polycentric cities, UC identification has become a complex task, challenging the knowledge of urban planners. Against this backdrop, scholars have sought to identify UCs in polycentric cities based on different indicators, including employment density [15-18], housing (or land) price gradient [19-21], and population distribution [22,23]. The majority of these studies have focused on the socioeconomic attributes of urban systems without clearly delineating the linkages between UC distribution and urban functions $[6,9,24]$.

This limitation may adversely impact the effectiveness of UC identification. According to Zhong, Schläpfer, Müller Arisona, Batty, Ratti, and Schmitt [24], and Sun, Fan, Li, and Zipf [7], a UC is a cluster of venues geographically close to each other that serve multiple functions to effectively fulfill the diverse demands of their urban residents. Based on this view, the identification of UCs should comprehensively reflect the functional characteristics of those cities. Since one primary purpose of USS analysis is to help planners design effective measures for improving the urban functions of cities [9], as the key step of USS, UC identification should reflect the impact of UC distribution on urban functions. A clear understanding of the connections between UCs and urban functions is an important part of what enables urban planners to balance resource allocation and optimize planning strategies [24]. Therefore, studies should be conducted to explore UCs from the perspective of urban functions.

Based on point-of-interest (POI) data, this study proposes a theoretical framework for UC identification, in which urban functions can be effectively analyzed and captured. Broadly speaking, this framework contains three layers. In the first, POI data are collected and grouped into categories based on their contributions to urban functions. In the second layer, the density-based spatial clustering of application with noise (DBSCAN) algorithm is performed to identify UCs based on the spatial and functional distribution of POIs. The effectiveness of this UC identification is then evaluated using the clustering validation index based on nearest neighbors (CVNN) method. In the third layer, the results of the UC identification are visualized on ArcGIS, which generates displays to help users conceptualize the UC distribution of a city. To illustrate the application of this three-layer UC identification framework, Beijing was selected as an illustrative case for five types of functional UCs. The findings of this study are expected to contribute to the body of knowledge regarding USS analyses, especially UC identification.

\section{Literature Review}

Scholars have analyzed the implications of UCs from diverse theoretical perspectives, and some claim that UCs should be determined based on urban employment distribution. McDonald [25] defined a UC as an area whose gross employment density significantly exceeded that of contiguous zones. Consistent with this view, Giuliano and Small [26] identify UCs by setting two fixed employment thresholds-a minimum employment density of 10 per acre and a minimum gross employment of 10,000. To accurately evaluate the employment density of a UC, OLS regression [16] and locally weighted regression [17] methods have been adopted based on statistical data. Giuliano, et al. [27] and 
Huang, Liu, Zhao, and Zhao [10] utilized similar methods for UC identification, but their findings showed that the employment thresholds of different cities should be modified according to these cities' basic conditions. In sum, floating employment thresholds should be used to predict the UC distribution of cities.

Some scholars have argued that UCs should be identified from the perspective of population distribution. For example, Feng, Wang, and Zhou [22] claimed that the population density of a UC should be significantly higher than that of surrounding areas. Based on a statistical analysis of local population data, the authors proposed an empirical model for identifying UCs in megacities but failed to offer any population thresholds for UC identification. Liu and Wang [23] proposed such thresholds, according to which a UC was defined as a cluster of three or more grids containing a total greater than 100,000. Based on these population thresholds, the authors investigated the UCs of 318 cities in China. In terms of analyzing UCs based on urban population, the majority of previous studies have focused on fixed population thresholds rather than floating indicators. Such studies, however, essentially regarded UCs as local peaks of urban population distribution in cities.

Scholars also explored the implications of UCs from the perspective of human activities. Sun, Fan, $\mathrm{Li}$, and Zipf [7] stated that UCs were critical nodes of urban areas where human activities tended to concentrate. Using location-based social networking (LBSN) data, these authors detected potential UCs according to human mobility. By analyzing night-time light imagery and social media check-in maps, Cai, Huang, and Song [12] proposed a novel method for identifying UCs based on human behavior and activity. They concluded that the human activity density of a UC should be higher than that of other city areas. Generally, thanks to the development of big data technologies, researchers can now utilize large volumes of human activity-related data to capture the dynamics of UCs in cities.

Due to the attractiveness of UCs, scholars found that housing (or land) prices in UCs were much higher than in other urban areas [19-21]. Thus, researchers also utilized housing (or land) price indicators to identify UCs, the majority of which employed a hedonic price model or a price gradient model. For example, Qin and Han [19] compared the explanatory power of a monocentric hedonic price model with that of a polycentric one, and confirmed four traditional UCs in Beijing. Wen and Tao [20] analyzed the housing price gradient of Hangzhou, and identified three UCs based on price analysis. Using official land transaction data from 2008 to 2012, Zou, Mason, and Zhong [21] traced the evolution of UCs in Beijing by examining dynamic land price gradients. In these price-oriented studies, the researchers focused on the housing (or land) price gaps between UCs and their surrounding areas rather than the price thresholds of UCs.

In sum, although scholars have discussed the implications of UCs from diverse academic angles, most have focused on the socioeconomic and human activity-related characteristics of UCs [28]. In fact, few studies aiming to detect UCs have sufficiently considered urban functions. To attract population and socioeconomic activity, UCs should possess powerful functions that can effectively satisfy the diverse demands of urban residents [24]. From this perspective, UCs should be identified based on their contribution to urban functions. In addition, revealing the links between urban functions and urban forms is one of the primary purposes of USS analyses $[6,9,24,29]$. As an important step of these analyses, the identification of UCs should fully reflect the distribution of functions throughout the city. Therefore, studies should be conducted to develop a framework for UC identification based on urban function.

\section{Model Development}

\subsection{Points-of-Interest (POIs) and Their Links with Urban Functions}

A POI denotes a geographical location that can attract specific interests and satisfy the corresponding demands of the population [7,30]. POIs can effectively reflect the functional characteristics of different geographical locations [31]. Due to this benefit, POI data have been widely used to analyze the spatial distributions of urban functions in previous studies [32-34]. 
Compared with statistical data (e.g., population and housing prices), large volumes of POI data can be easily achieved in real time [35], which enables researchers to accurately capture the dynamics of urban function evolution.

Given the aforementioned benefits, POI data were utilized in this study to link UC identification with urban function analysis. First, we extracted POI data from electronic map databases and classified them by their contributions to different urban functions. Based on their geographical proximities, POIs with similar urban functions were then grouped into a few functional UCs, using the DBSCAN algorithm. Next, CVNN was utilized to evaluate the effectiveness of UC identification. Lastly, spatial distributions of UCs with diverse urban functions were visualized on the ArcGIS platform. As summarized in Figure 1, the theoretical framework for UC identification divides into three layers-data classification, calculation, and visualization.

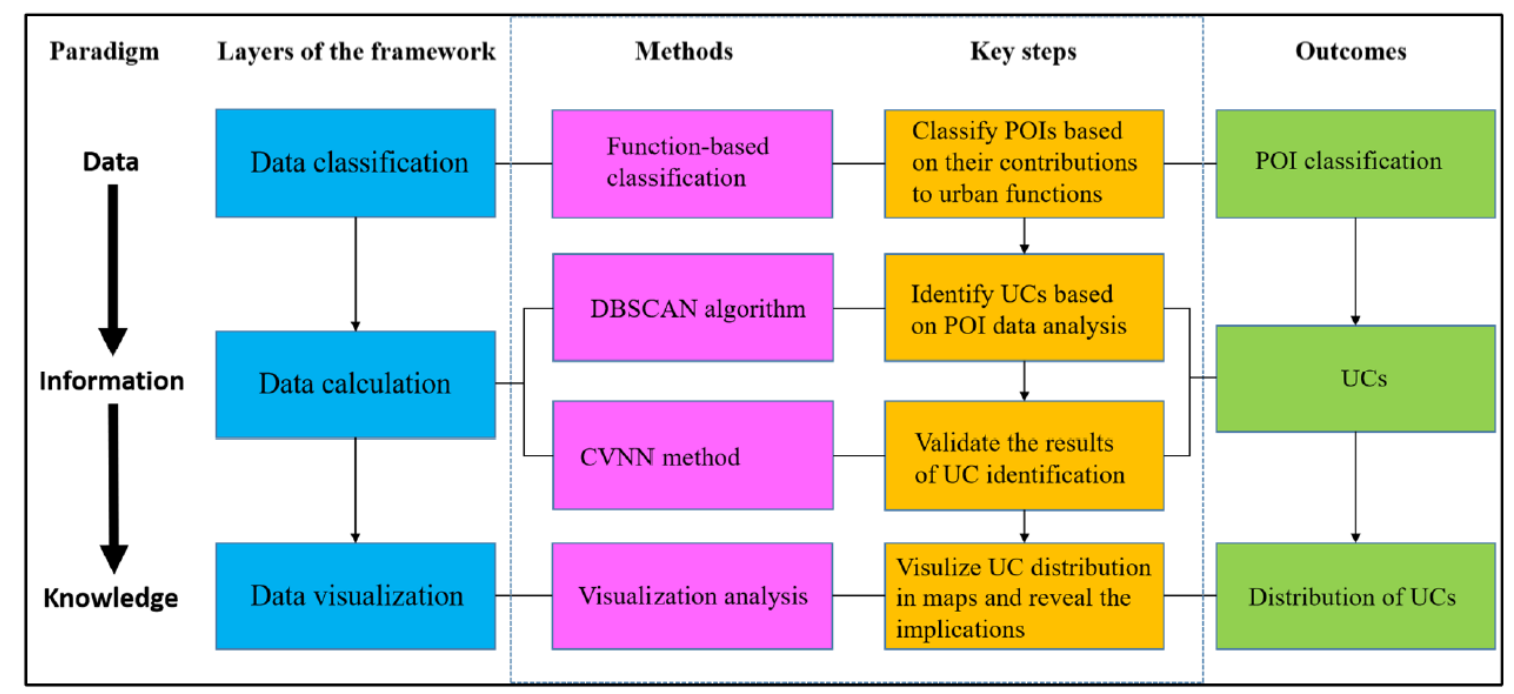

Figure 1. Framework for urban center (UC) identification and analysis.

\subsection{Data Classification Layer}

In the data classification layer, POI data were collected and classified based on their contributions to urban functions. Generally, there are two main sources for POI data-social media (e.g., Twitter, Foursquare, Facebook, Flickr, Sina Weibo) and electronic maps (e.g., OpenStreetMap, Google Maps, Baidu Map). In this study, we collected POI data from electronic maps because the geographical coverage of electronic map-based data is typically wider than with social media-based data [36]. In addition, POI data from social media are provided by ordinary urban residents and not validated further by professional authorities [37], whereas data derived from electronic maps are typically offered by professional companies such as Google and Baidu. Thus, electronic map-based data are widely considered to be more accurate [38]. The POI data used in our UC identification framework could be gathered easily from databases such as the official websites of OpenStreetMap, Google Maps, and Baidu Map.

To effectively link POI data with urban functions, many scholars have classified POIs according to their contribution to urban functions $[32,33,35]$. Consistent with these studies, we also grouped the collected POI data into a few categories from the perspective of urban functions. The principles underlying the POI classification are displayed in Table 1 and are consistent with relevant studies. POIs within the same category make similar contributions to urban functions. The primary urban functions analyzed in this study are residence, education, catering, shopping, and leisure and recreation. Accordingly, the POIs used by our UC identification framework were classified into five functional categories. However, it is worth noting that researchers can adopt other principles for classifying POIs by function. 
Table 1. Point-of-interest (POI) classification.

\begin{tabular}{|c|c|c|c|c|}
\hline NO. & Category of POI & POI & POI Implication & Reference \\
\hline 1 & Residence & Residence & Residential area, villa, dormitory, etc. & {$[6,8,31,33,34,39]$} \\
\hline 2 & Education & $\begin{array}{l}\text { Research and } \\
\text { education }\end{array}$ & $\begin{array}{l}\text { University, college, middle school, } \\
\text { kindergarten, research institution, } \\
\text { vocational school, primary school, } \\
\text { training center, private school, etc. }\end{array}$ & {$[6,8,31,33,34,36,39]$} \\
\hline 3 & Catering & Catering service & $\begin{array}{l}\text { Chinese restaurant, foreign restaurant, } \\
\text { fast-food restaurant, bakery, café, tea } \\
\text { house, pub, bar, etc. }\end{array}$ & {$[6,8,31,33,35,36]$} \\
\hline 4 & Shopping & Shopping service & $\begin{array}{l}\text { Shopping mall, convenience store, } \\
\text { supermarket, household appliance store, } \\
\text { electronic product store, furniture and } \\
\text { hardware store, etc. }\end{array}$ & {$[6,8,31,33-36]$} \\
\hline \multirow[t]{2}{*}{5} & \multirow[t]{2}{*}{$\begin{array}{l}\text { Leisure and } \\
\text { recreation }\end{array}$} & $\begin{array}{l}\text { Sport and leisure } \\
\text { service }\end{array}$ & $\begin{array}{l}\text { Stadium, golf, swimming pool, bowling, } \\
\text { gym, fitness, entertainment venue, leisure } \\
\text { facility, movie theater, art gallery, etc. }\end{array}$ & {$[6,8,31,33-36]$} \\
\hline & & Place of interest & Park, square, zoo, church, scenic spot, etc. & [33-36] \\
\hline
\end{tabular}

\subsection{Data Calculation Layer}

According to Zhong, Schläpfer, Müller Arisona, Batty, Ratti, and Schmitt [24], a UC should be determined according to two principles: First, the elements of a UC should have similar functions to satisfy the demands of urban residents; and second, these elements should be geographically close to each other. Following the first principle, in the first layer of the framework, POIs were classified into five categories based on their contribution to various urban functions. Following the second principle, in the data calculation layer, POIs within the same category were grouped into a few UCs according to geographical proximity.

The DBSCAN algorithm was utilized to gather neighboring POIs into one UC, and CVNN was employed to evaluate the effectiveness of this UC identification. The DBSCAN algorithm originates from the field of knowledge discovery [40]. As one of the most widely used algorithms for clustering [41], DBSCAN can effectively extract useful information from a large amount of spatial data within a relatively short time [42,43]. In addition, DBSCAN is an unsupervised clustering algorithm, which does not rely heavily on researcher knowledge $[30,44]$. Therefore, this algorithm can be used to mitigate a researcher's subjective biases. Given these benefits, DBSCAN was instrumental to this study.

The primary processes of the DBSCAN algorithm are displayed in Figure 2. Before performing DBSCAN, users determine two parameters, the radius of a POI's neighborhood (Eps) and the minimum number of POIs contained in a POI's neighborhood (MinPts). In this study, Eps is estimated by the evaluation model proposed by Starczewski and Cader [45], and MinPts is calculated by the evaluation model proposed by Zhou, et al. [46]. Compared with other parameter setting methods, those proposed by Starczewski and Cader [45] and Zhou, Wang, and Li [46] do not rely heavily on the researcher's knowledge, which helps prevent subjective biases. In these two methods, users must set the number of initial clustering centers, i.e., k-value. The selection of effective $\mathrm{k}$-values can be based on previous studies by Ester, et al. [47], Zhou, Wang, and Li [46], Gaonkar and Sawant [44], Karami and Johansson [48], and Starczewski and Cader [45]. 


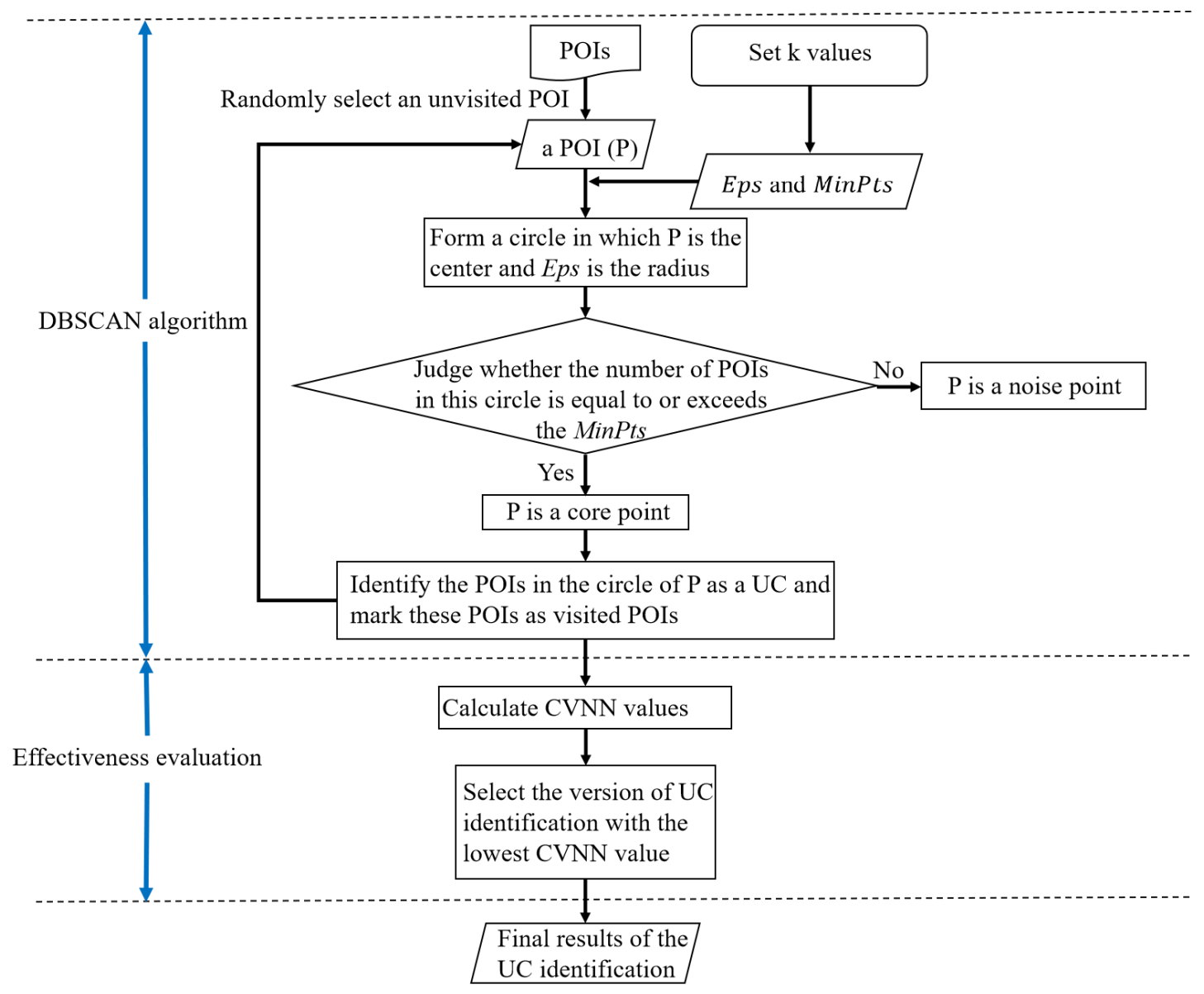

Figure 2. Data calculation layer.

As shown in Figure 2, POIs in the same category were inputted into the data calculation layer. To identify a cluster of neighboring POIs (i.e., a UC), the DBSCAN algorithm started by randomly selecting an unvisited POI $(\mathrm{P})$ as the core of a circle. In this circle, Eps was set as the radius. If the number of POIs within the boundary of this circle was equal to or greater than the MinPts, then P was considered to be a core point of a UC. If the POIs were fewer than the MinPts, then P was regarded as a noise point and not the core of any UCs. Then, all POIs within the circle of the core point $\mathrm{P}$ were gathered to form a UC. These POIs were marked as visited POIs and excluded from the next round of random selection. Procedures were repeated until all potential UCs were identified.

After performing the DBSCAN algorithm, the effectiveness of UC identification was evaluated [49-51]. Consistent with the study conducted by Liu, Li, Xiong, Gao, Wu, and Wu [51], CVNN was employed to compare the different versions of UC identification with diverse k-values. Typically, the best version of UC identification has the lowest CVNN value.

\subsection{Data Visualization Layer}

In the data visualization layer, the distribution of UCs with diverse urban functions was visualized on ArcGIS. UCs with similar functions were summarized in a single image. Relevant planning policies should be reviewed to explain the implications of UC distributions. In the following section, the UCs of Beijing are identified using our proposed framework. 


\section{Case Study}

\subsection{Study Area}

This study selected Beijing as the study area for several reasons. First, as capital of China, Beijing was named by the Globalization and World Cities Research Network as a first-tier global city. Rapid economic growth and urbanization have enabled Beijing to become a polycentric city [10]. Compared with monocentric cities, the UC identification of Beijing is more complex and difficult, which makes it an exemplary case. Second, its population is increasing substantially, reaching 21.70 million in 2017 [52]. Since such local population growth has placed great strain on the urban functions of traditional UCs, the city government has issued a series of planning policies for function decentralization [10]. Against this backdrop, identifying the UCs of Beijing from the perspective of urban functions provides a valuable measure for the effectiveness of the city's decentralization policies. Due to these benefits, Beijing serves as an illustrative case for the application of the proposed UC identification framework.

Situated in northern China, Beijing consists of 16 administrative districts and covers $16,410.54 \mathrm{~km}^{2}$ [52]. The city has six ring roads, with six administrative districts on the Sixth Ring Road-Xicheng, Dongcheng, Chaoyang, Haidian, Shijingshan, and Fengtai (see Figure 3). Typically, these districts are considered the inner city of Beijing. The economic conditions and infrastructure development of the six inner districts are better than those of the other districts. As a result, more than $55 \%$ of Beijing's population concentrates in these districts [52], which presents a significant challenge to the urban functions of the traditional inner city, especially the core area within Fifth Ring Road.

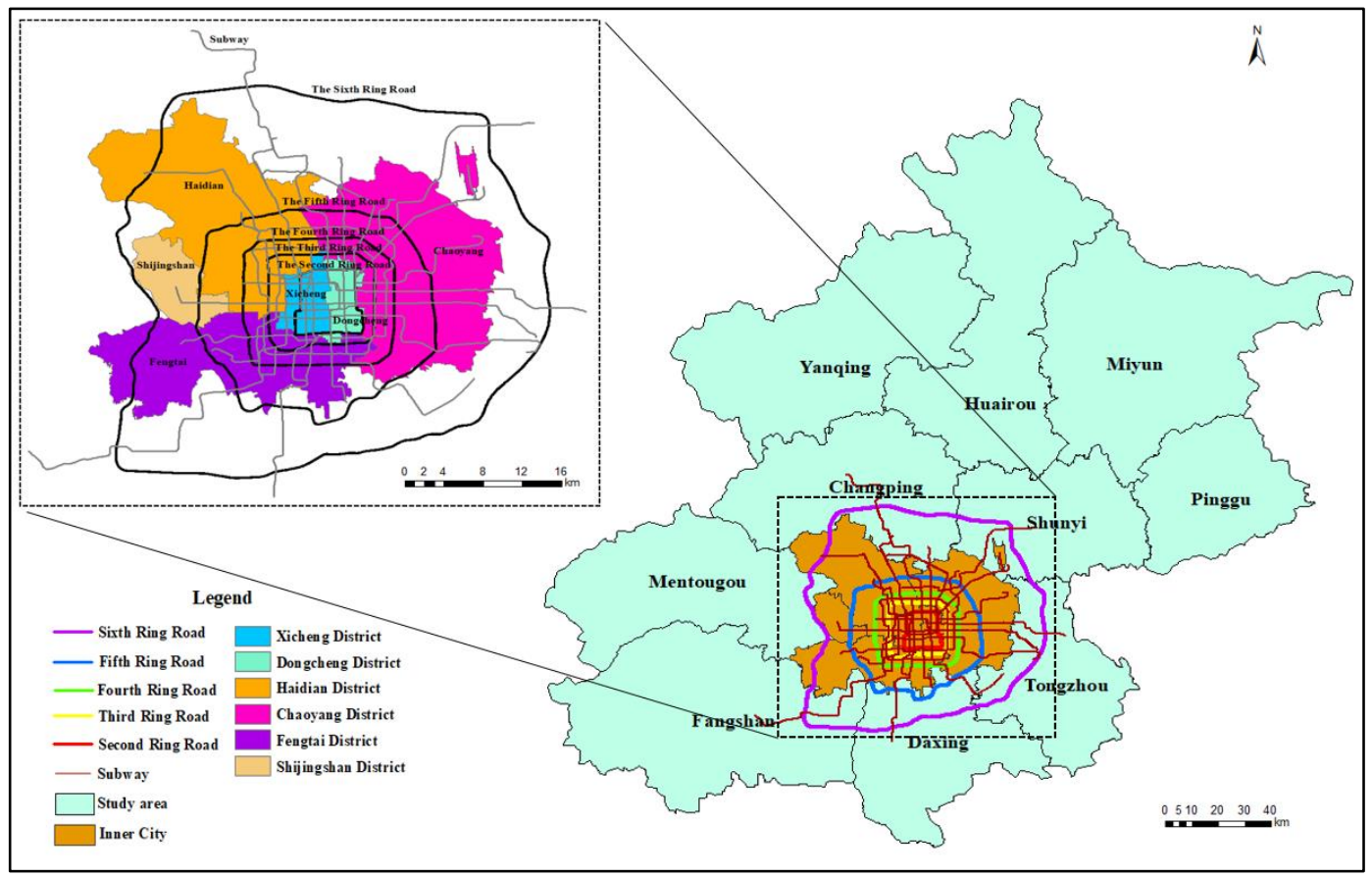

Figure 3. Study area.

To disperse pressure from the core of the inner city, Beijing has planned to develop four inner UCs within Fifth Ring Road, as shown in Figure 4. Furthermore, ten urban fringe areas around Fifth Ring Road and 11 new towns outside Sixth Ring Road have been identified as key development areas for dispersing the population from the inner city. According to the 2016-2035 Urban Master Plan of Beijing, the total population of the six inner districts will likely be reduced by $15 \%$ by the end of 2020. To meet this target, the urban functions of these urban fringe areas and new towns will be significantly improved. 


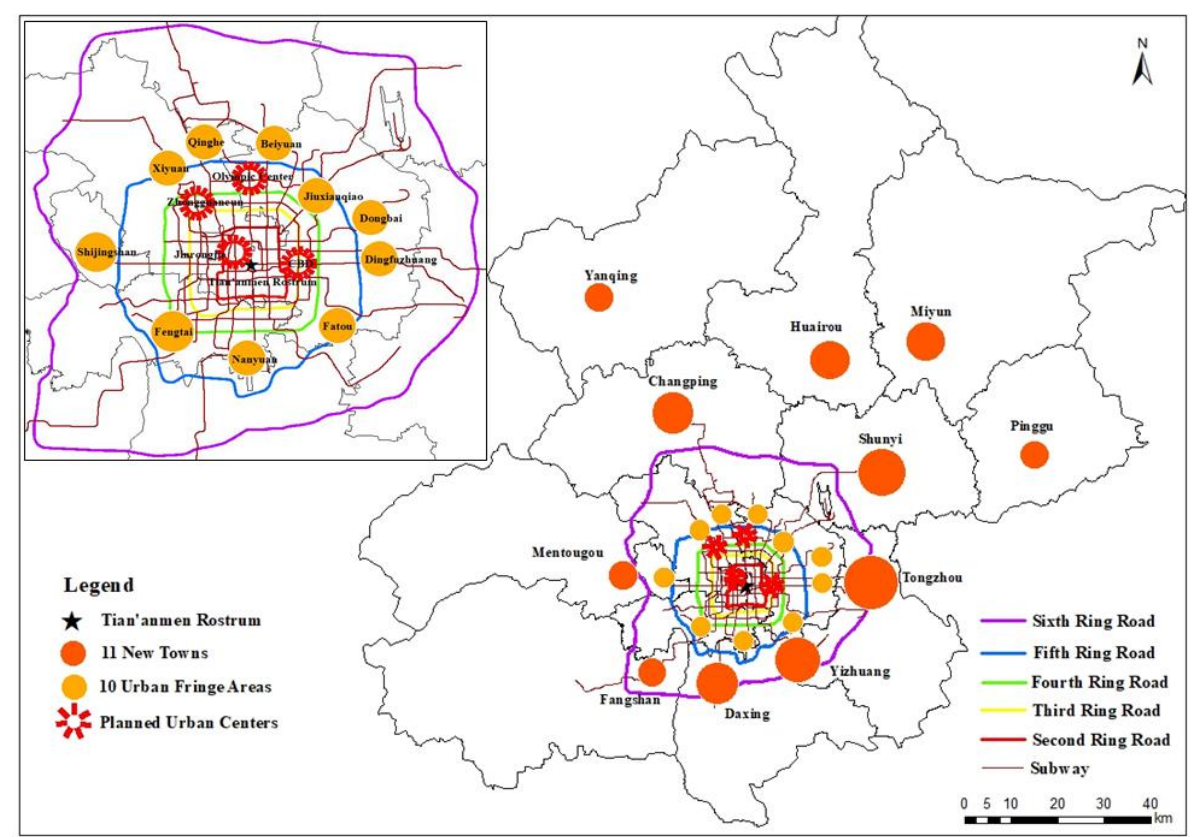

Figure 4. Urban planning zones (note: Figure developed from Urban Master Plans of Beijing (1991-2010, 2004-2020, 2016-2035).).

\subsection{Data}

For this study, 487,969 geo-tagged POIs in Beijing were gathered from the official website of Baidu Map (a popular map search platform in China, https://map.baidu.com) in June 2019. The collected data included name, latitude and longitude, district, address, and functional characteristics of 487,969 POIs. Among these, 142,044 did not significantly reflect the five types of urban functions in Table 1. Based on the classification principles in Table 1, a total of 345,925 POIs were used and grouped into five categories of urban function. The function distribution is displayed in Table 2. Shopping and catering POIs are much more numerous than POIs of other categories. This indicates that the shopping and catering industry of Beijing has been well developed.

Table 2. Function distribution of POIs in Beijing.

\begin{tabular}{ccc}
\hline Category & Count & Proportion \\
\hline Residence & 18,506 & $5.35 \%$ \\
Education & 40,546 & $11.72 \%$ \\
Catering & 79,624 & $23.02 \%$ \\
Shopping & 164,352 & $47.51 \%$ \\
Leisure and Recreation & 42,897 & $12.40 \%$ \\
\hline
\end{tabular}

\subsection{Results of Urban Center (UC) Identification}

Consistent with previous studies, to evaluate the parameters of Eps and MinPts, four k-values were selected-3, 4, 5, and $6[44,45,48]$. By running the DBSCAN algorithm, UCs were then identified based on the function classification and geographical distributions of POIs. As shown in Table 3, different initial k-values can generate different versions of UC distribution. According to Liu, Li, Xiong, Gao, Wu, and $\mathrm{Wu}$ [51], the best version of UC distribution has the lowest CVNN value. Thus, nine residential UCs, 14 educational UCs, 55 catering UCs, 104 shopping UCs, and 11 leisure and recreation UCs were identified from different function categories of POIs. The final results of this UC distribution were visualized on ArcGIS. 
Table 3. Overall results of UC identification.

\begin{tabular}{|c|c|c|c|c|c|}
\hline \multirow{2}{*}{ POI Category } & \multirow{2}{*}{$k$-value } & \multicolumn{2}{|c|}{ Parameters of DBSCAN } & \multirow{2}{*}{ Number of UCs (POI Clusters) } & \multirow{2}{*}{ CVNN } \\
\hline & & Eps & MinPts & & \\
\hline \multirow{4}{*}{ Residence } & 3 & 1227.60 & 77 & 19 & 2.0000 \\
\hline & 4 & 1673.10 & 132 & 9 & 0.9364 \\
\hline & 5 & 1379.20 & 94 & 14 & 1.6941 \\
\hline & 6 & 1706.10 & 136 & 9 & 0.9249 * \\
\hline \multirow{4}{*}{ Education } & 3 & 903.43 & 136 & 30 & 1.9840 \\
\hline & 4 & 808.36 & 114 & 35 & 1.9751 \\
\hline & 5 & 1056.40 & 176 & 20 & 1.3962 \\
\hline & 6 & 1315.5 & 254 & 14 & 0.7927 * \\
\hline \multirow{4}{*}{ Catering } & 3 & 293.32 & 51 & 263 & 2.0000 \\
\hline & 4 & 681.31 & 154 & 57 & 1.1139 \\
\hline & 5 & 896.94 & 229 & 57 & 1.2145 \\
\hline & 6 & 694.97 & 158 & 55 & 1.0997 * \\
\hline \multirow{4}{*}{ Shopping } & 3 & 198.76 & 105 & 188 & 1.3885 \\
\hline & 4 & 446.54 & 228 & 104 & $1.3467^{*}$ \\
\hline & 5 & 580.45 & 301 & 84 & 2.0000 \\
\hline & 6 & 718.92 & 382 & 62 & 1.9796 \\
\hline \multirow{4}{*}{$\begin{array}{l}\text { Leisure and } \\
\text { Recreation }\end{array}$} & 3 & 720.98 & 76 & 46 & 1.6182 \\
\hline & 4 & 971.78 & 108 & 25 & 1.5098 \\
\hline & 5 & 1674.10 & 232 & 11 & 1.2369 * \\
\hline & 6 & 1942.9 & 293 & 10 & 1.5562 \\
\hline
\end{tabular}

Note: Minimum CVNN is denoted by *, which means the corresponding parameters and the number of UCs are optimal.

\subsubsection{Residential UCs}

According to the 1991-2010, 2004-2020, and 2016-2035 Urban Master Plans of Beijing, ten urban fringe areas were developed to disperse the population of the inner city area [53]. As shown in Figure 5, residential decentralization of the inner city is significantly aided by five urban fringe areas-Shijingshan, Qinghe, Fengtai, Qingfuzhuang, and Jiuxianqiao. Moreover, the majority of these fringe areas are covered by residential UCs. Additionally, 11 new towns have been established to motivate urban residents to relocate from the inner city to areas outside of Sixth Ring Road. Residential UCs have been developed in three new towns-Huairou, Minyun, and Changping-which emerged as a result of the new town development policies. However, the biggest residential UCs (i.e., with 9109 POIs) are located within Fifth Ring Road, the core area of the inner city. By contrast, the residential UCs of the three new towns only have 801 POIs. Such unbalanced distribution of residential resources implies that the contribution of these new town development policies has been relatively limited. 


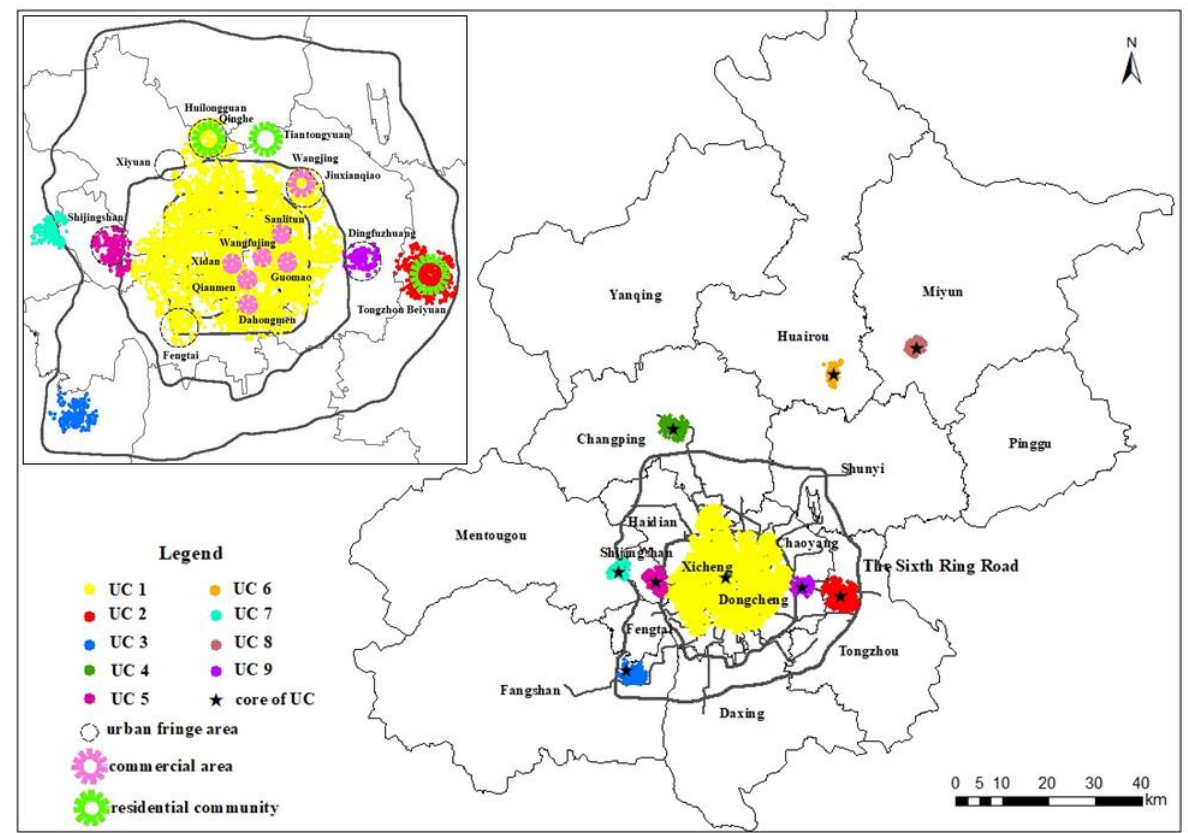

Figure 5. Residential UCs.

\subsubsection{Educational UCs}

Figure 6 displays the 14 educational UCs identified in this study. Compared with residential UCs, the distribution of educational UCs is even less balanced. In other words, around $95 \%$ of education resources are concentrated within or along Sixth Ring Road. Only one of the top ten educational UCs is located outside of Sixth Ring Road, situated in Changping District.

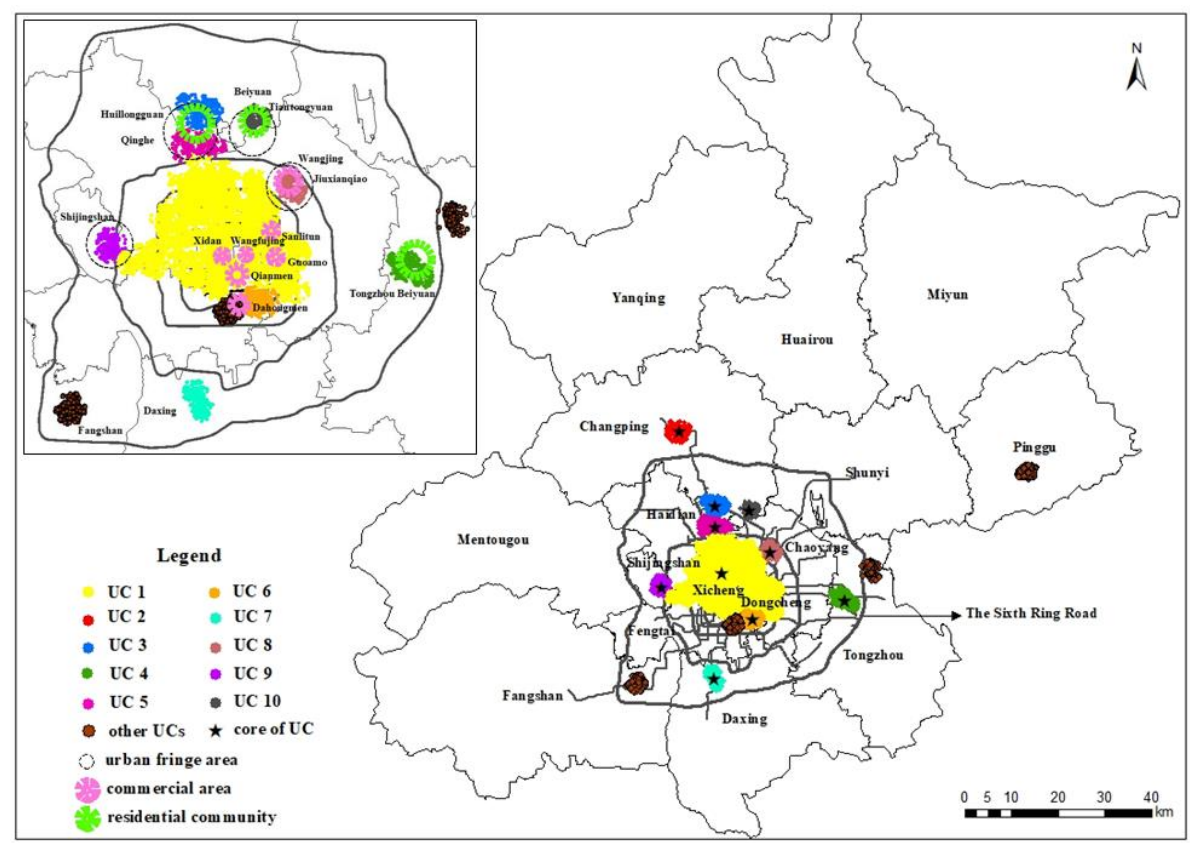

Figure 6. Educational UCs.

As Figure 6 shows, four urban fringe areas—Shijingshan, Qinghe, Beiyuan, and Jiuxianqiao-are covered by educational UCs, which implies that urban fringe development policies have positively impacted the decentralization of education resources. However, the new town development policies 
have contributed somewhat less toward dispersing educational resources because the majority of educational POIs still concentrate within Sixth Ring Road.

Additionally, Beijing has developed three super-large residential communities-Huilongguan, Tiantongyuan, and Tongzhou Beiyuan-all of which have close geographical relationships with educational UCs. This indicates that the construction of large residential communities may be an effective approach for the decentralization of educational resources.

\subsubsection{Catering UCs}

As shown in Figure 7, this study identifies 55 catering UCs distributed across the 17 administrative districts, showing a clear trend of decentralization. From Figure 7, it is also evident that the development of urban fringe areas and new towns has positively impacted the decentralization of catering resources. Seven of the ten urban fringe areas have at least one catering UC along Fifth Ring Road. Eight catering UCs are located in Daxing District, Fangshan District, Changping District, Shunyi District, Yanqing District, Huairou District, Miyun District, and Pinggu District, respectively, all of which are outside of Sixth Ring Road.

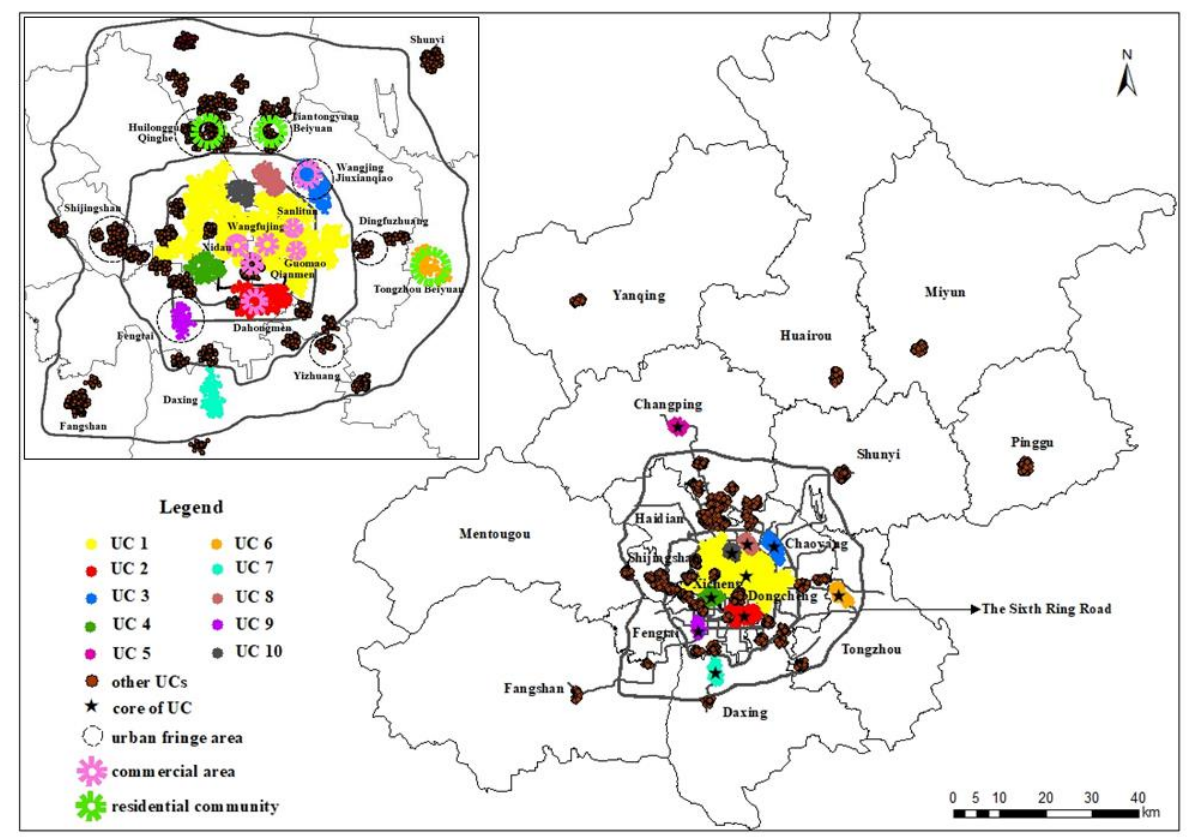

Figure 7. Catering UCs.

Unlike the two aforementioned types of functional UCs, however, catering UCs are distributed irregularly. Each administrative district has at least one catering UC apart from the yellow area. The number of catering UCs in Changping District, Fengtai District, and Chaoyang District is greater than in other regions. Additionally, from Figure 7, one can see that the distribution of catering UCs closely resembles the locations of super-large residential communities and commercial areas.

\subsubsection{Shopping UCs}

Figure 8 displays the 104 shopping UCs identified in this study. Their spatial distribution is wider than that of the aforementioned types of UCs. To some degree, the development of urban fringe areas and new towns has positively impacted the decentralization of shopping POIs. Eight of the ten urban fringe areas and all of the 11 new towns have shopping UCs; however, about $90 \%$ of shopping UCs are concentrated within Sixth Ring Road, which indicates that decentralization of shopping POIs is still relatively low. 


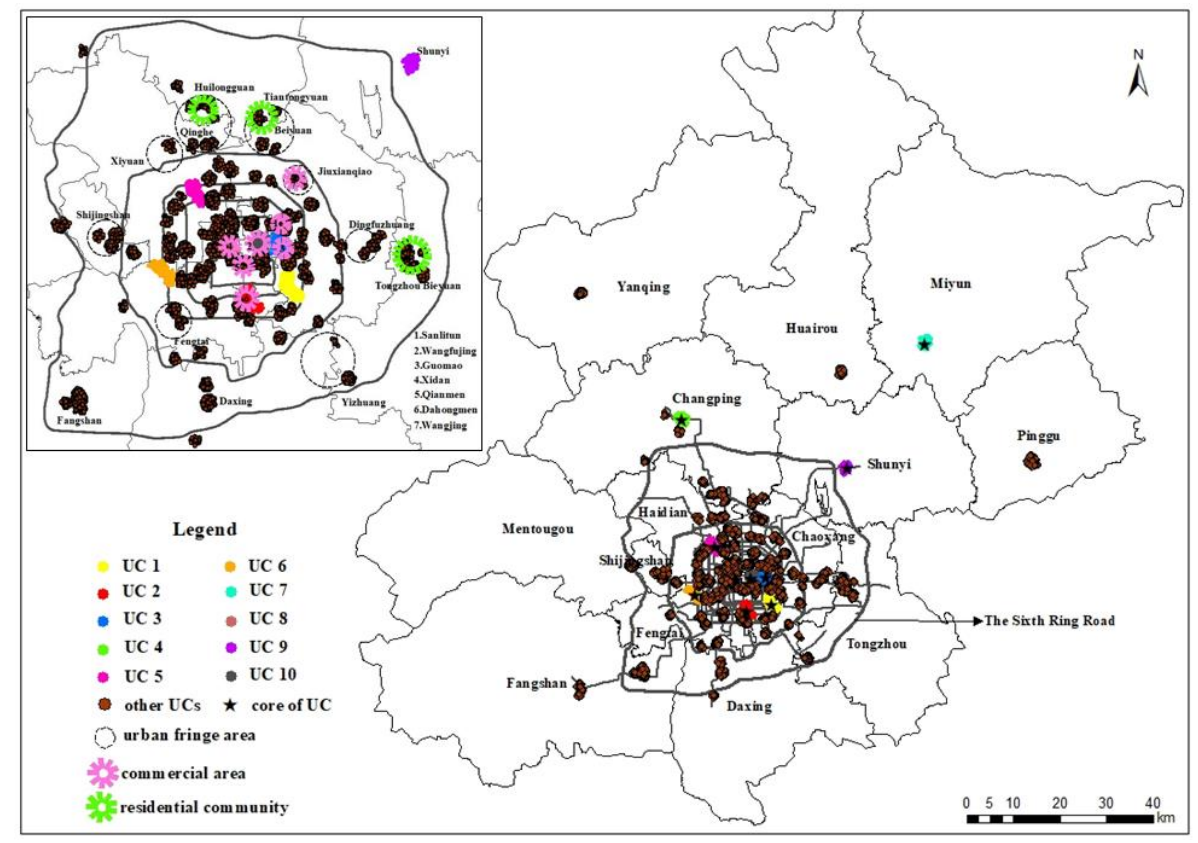

Figure 8. Shopping UCs.

In contrast to other types of UCs, there are no significant distinctions among different shopping UCs in terms of spatial scale. Shopping UCs within Fourth Ring Road cover seven famous commercial areas-the Wangfujing and Qianmen in Dongcheng District, the Sanlitun and Guomao in Chaoyang District, the Xidan in Xicheng District, the Zhongguancun in Haidian District, and the Dahongmen in Fengtai District. Additionally, each of the three super-large residential communities has at least one shopping UC, suggesting that the development of large communities attracts shopping resources.

\subsubsection{Leisure and Recreation UCs}

As shown in Figure 9, this study identifies 11 leisure and recreation UCs, the majority of which are concentrated within Sixth Ring Road. Specifically, Changping District has three leisure and recreation UCs, whereas Tongzhou District has two, and other districts have, at most, one. Moreover, as can be seen, the development of urban fringe areas and super-large communities has significantly contributed to the decentralization of leisure and recreation POIs in the inner-city area. Seven of the ten urban fringe areas and all of the super-large communities have been covered by leisure and recreation UCs.

In addition, different leisure and recreation UCs have diverse development modes. For example, UCs 4 and 10 are geographically close to large-scale residential communities (i.e., Huilongguan and Tiantongyuan) whose development is driven by the huge demands of community residents; UCs 3, 7, and 9 are concentrated in scenic spots, such as Xiangshan Park, Beijing Botanical Garden, World Park, and Shidu Scenic Spot, where development is driven by their scenic resources; UCs 2 and 8 are close to Songzhuang Art District and China International Exhibition Center, where development is driven by its cultural resources.

\subsubsection{Summary of UCs in Different Urban Planning Zones}

To test the effectiveness of Beijing's decentralization policies, the distribution of UCs in different urban planning zones is summarized in Table 4. The development of urban fringe areas and new towns has generally contributed to the functional decentralization of Beijing. Compared with new towns, urban fringe areas have developed unevenly. Three fringe areas in particular-Dongba, Fatou, and Nanyuan-lack functional UCs. However, each of the other seven urban fringe areas has at least four types of functional UCs. Also, with the exception of the Yanqing District, each new town has at least three types of functional UCs. Although new towns were developed more evenly than urban 
fringe areas, they do not necessarily contribute more to decentralization. As can be seen, the distribution of functional UCs is more balanced within than outside of Sixth Ring Road. With respect to the distribution of urban functions, catering, and shopping, UCs have wider geographical coverage than other types of UCs, which indicates that the decentralization of residential, education, leisure and recreation resources is important for improvement.

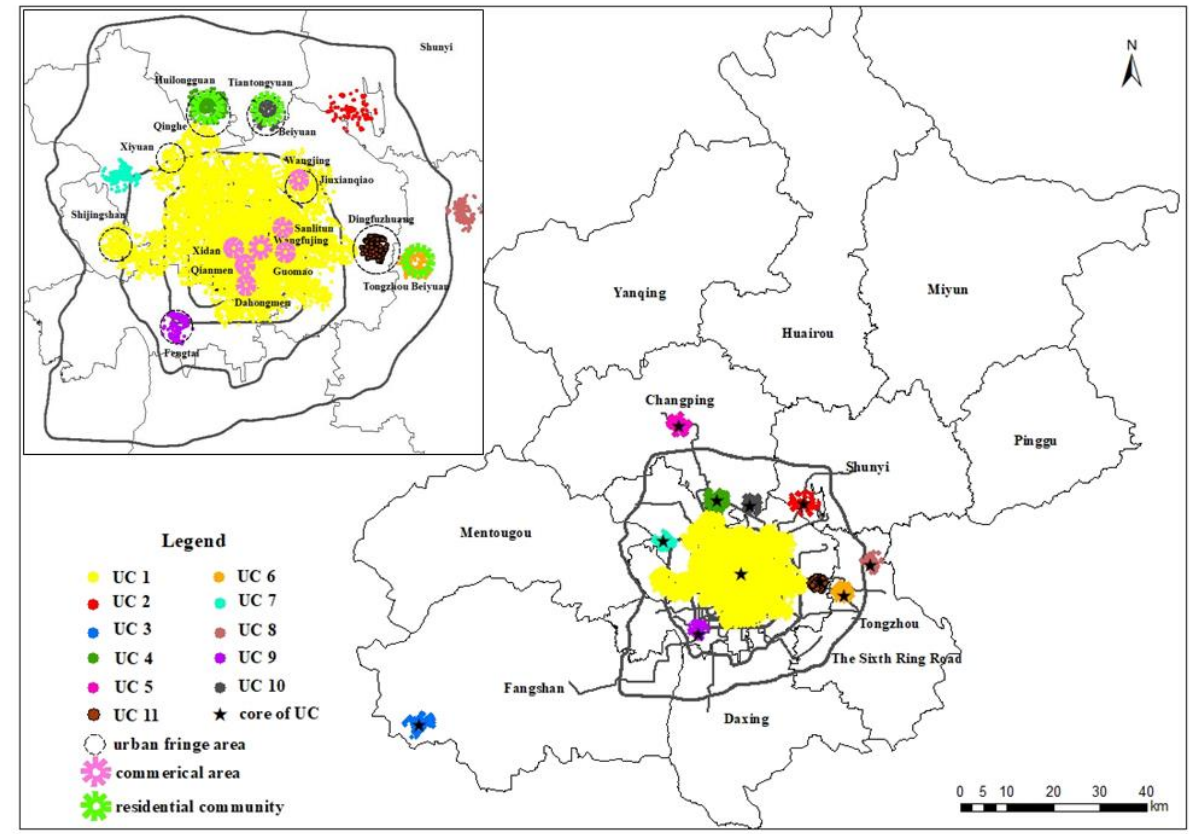

Figure 9. Leisure and recreation UCs.

Table 4. UCs in different urban planning zones.

\begin{tabular}{|c|c|c|c|c|c|c|}
\hline \multirow{2}{*}{\multicolumn{2}{|c|}{ Urban Planning Zone }} & \multicolumn{5}{|c|}{ UCs with Different Functions } \\
\hline & & Residence & Education & Catering & Shopping & Leisure and Recreation \\
\hline \multirow{10}{*}{$\begin{array}{c}\text { Urban fringe } \\
\text { areas }\end{array}$} & Qinghe & $\sqrt{ }$ & $\sqrt{ }$ & $\sqrt{ }$ & $\sqrt{ }$ & $\sqrt{ }$ \\
\hline & Beiyuan & $x$ & $\sqrt{ }$ & $\sqrt{ }$ & $\sqrt{ }$ & $\sqrt{ }$ \\
\hline & Xiuxianqiao & $\sqrt{ }$ & $\sqrt{ }$ & $\sqrt{ }$ & $\sqrt{ }$ & $\sqrt{ }$ \\
\hline & Dongba & $x$ & $x$ & $x$ & $x$ & $x$ \\
\hline & Dingfuzhuang & $\sqrt{ }$ & $x$ & $\sqrt{ }$ & $\sqrt{ }$ & $\sqrt{ }$ \\
\hline & Fatou & $x$ & $x$ & $x$ & $x$ & $x$ \\
\hline & Nanyuan & $x$ & $x$ & $x$ & $x$ & $x$ \\
\hline & Fengtai & $\sqrt{ }$ & $x$ & $\sqrt{ }$ & $\sqrt{ }$ & $\sqrt{ }$ \\
\hline & Shijingshan & $\sqrt{ }$ & $\sqrt{ }$ & $\sqrt{ }$ & $\sqrt{ }$ & $\sqrt{ }$ \\
\hline & Xiyuan & $\sqrt{ }$ & $\sqrt{ }$ & $x$ & $\sqrt{ }$ & $\sqrt{ }$ \\
\hline \multirow{11}{*}{ New towns } & Changping & $\sqrt{ }$ & $\sqrt{ }$ & $\sqrt{ }$ & $\sqrt{ }$ & $\sqrt{ }$ \\
\hline & Shunyi & $x$ & $x$ & $\sqrt{ }$ & $\sqrt{ }$ & $\sqrt{ }$ \\
\hline & Tongzhou & $\sqrt{ }$ & $\sqrt{ }$ & $\sqrt{ }$ & $\sqrt{ }$ & $\sqrt{ }$ \\
\hline & Yizhuang & $x$ & $x$ & $\sqrt{ }$ & $\sqrt{ }$ & $x$ \\
\hline & Daxing & $x$ & $\sqrt{ }$ & $\sqrt{ }$ & $\sqrt{ }$ & $x$ \\
\hline & Fangshan & $\sqrt{ }$ & $\sqrt{ }$ & $\sqrt{ }$ & $\sqrt{ }$ & $\sqrt{ }$ \\
\hline & Mentougou & $\sqrt{ }$ & $x$ & $\sqrt{ }$ & $\sqrt{ }$ & $x$ \\
\hline & Yanqing & $x$ & $x$ & $\sqrt{ }$ & $\sqrt{ }$ & $x$ \\
\hline & Huairou & $\sqrt{ }$ & $x$ & $\sqrt{ }$ & $\sqrt{ }$ & $x$ \\
\hline & Miyun & $\sqrt{ }$ & $x$ & $\sqrt{ }$ & $\sqrt{ }$ & $x$ \\
\hline & Pinggu & $x$ & $\sqrt{ }$ & $\sqrt{ }$ & $\sqrt{ }$ & $\times$ \\
\hline
\end{tabular}

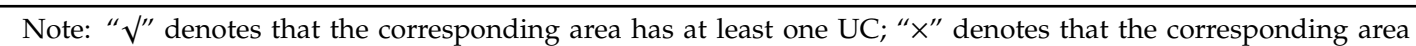
lacks UCs. 


\section{Discussion}

\subsection{Insights Generated from UC Distribution of Beijing}

According to the 2016-2035 Urban Master Plan of Beijing, population agglomeration has caused a number of urban development problems, such as traffic congestion, super-high housing prices, and environmental pollution [53]. To mitigate the population pressure, decentralization of urban functions has been identified as a vital strategy for the sustainable development of Beijing. Against this backdrop, Beijing is expected to become a polycentric city in the future. Based on the analyses of UC distribution in Section 4, this study confirms that Beijing is in transition from a monocentric to a polycentric city in terms of its distribution of urban functions. This finding is consistent with the study conducted by Huang, Liu, and Zhao [4] but differs from the view that Beijing has become a mature polycentric city in recent years $[6,8,12,19,23]$. The rationale is as follows.

On the one hand, the degree of urban function decentralization in Beijing is still relatively low. Moreover, the distribution of urban functions is extremely uneven, which leads to population aggregation in the inner city. According to the UC analyses, the largest residential UC has $78.24 \%$ of residential POIs; the largest educational UC covers $67.72 \%$ of educational POIs; the largest catering UC contains $41.91 \%$ of catering POIs; the largest shopping UC possesses $3.39 \%$ of shopping POIs; and the largest leisure and recreation UC has $79.72 \%$ of leisure and recreation POIs. These five UCs are located within Sixth Ring Road. With the exception of shopping resources, urban function resources still concentrate in these largest UCs, suggesting clearly monocentric characteristics. From this view, Beijing is not a mature polycentric city.

On the other hand, spatial distribution of functional POIs in Beijing has expanded. From Table 4, one can see that different types of UCs have been established in the ten urban fringe areas and 11 new towns, which indicates that the population decentralization policies of Beijing have positively impacted the decentralization of urban function. Additionally, from Figures 5-9, one can see that the development of super-large residential communities effectively facilitates urban function decentralization. The huge demands generated from super-large communities can attract resources and investments for urban function updating and UC development. Generally, the increasingly wide spatial distribution of UCs implies that the USS of Beijing has polycentric characteristics. Therefore, Beijing is neither monocentric nor polycentric but in transition.

Among the five types of functional UCs, catering and shopping UCs are distributed relatively evenly, which displays significantly polycentric features. Each administrative district of Beijing has at least one catering UC and one shopping UC. Therefore, to expedite Beijing's transition to a polycentric city, local governments should focus on the other three types of UCs.

In terms of decentralizing residential resources, the development of super-large residential communities may be effective. Since land prices in Beijing's inner-city areas are much higher than in the 11 new towns, the development of super-large residential communities in these new towns would effectively attract middle- and low-income inhabitants who cannot easily afford expensive housing [53].

To decentralize educational resources, the City Government of Beijing has motivated superior schools and universities to develop branch campuses in the 11 new towns. Thus far, more than 30,000 university teachers and students have moved to these new towns from inner city areas [54]. The construction of the Liangxiang Higher Education Park in the Fangshan new town and the Shahe Higher Education Park in the Changping new town has motivated numerous superior schools, universities, and research institutions to relocate to the suburbs.

The uneven distribution of leisure and recreation UCs was caused by historical factors [55]. Leisure and recreation resources show a close linkage with the spatial distribution of historical and cultural heritage. These types of heritage can be regarded as exclusive resources that cannot be easily reproduced. The majority of these heritage resources are located in the inner city of Beijing. To decentralize leisure and recreation resources, the City Government has planned to develop modern 
cultural industries in the 11 new towns [53]. For example, the Songzhuang Art District and the China International Exhibition Center were established in the new towns of Tongzhou and Shunyi, respectively, and rapidly grew into flourishing tourist resorts. In summary, a series of decentralization policies have been enacted to facilitate Beijing's transition from a monocentric to a polycentric city. In the near future, we expect Beijing to become a mature polycentric city.

\subsection{Theoretical and Practical Implications}

This study contributes theoretically to the area of USS analyses. First, whereas many previous studies identified UCs according to the socioeconomic characteristics of cities, e.g., population distribution, employment density, and housing (or land) prices [4,19-22], and the majority of these studies have paid insufficient attention to the functional features of UCs, this study proposes a framework for UC identification from the perspective of urban function distribution. Because the linkages between UC distribution and urban functions are critical for USS analyses and urban planning, this study's findings can assist urban planners to optimize their planning schemes.

Second, whereas the majority of previous studies identified UCs from statistical data that failed to capture the dynamic conditions of a city in real time [4,19-22], this study utilizes POI data to explore UCs. These POI data can be easily collected from databases such as OpenStreetMap, Google Maps, and Baidu Map. More importantly, these POI data record the dynamic conditions of cities in real time, which can help researchers understand the pathways and means by which the distribution of urban functions has evolved. For cities whose development was rapid, the proposed method of UC identification proved more effective than those of previous studies.

In addition to the aforementioned theoretical contributions, this study also offers some practical contributions. First, its findings can help practitioners to understand the distribution of urban functions in polycentric cities. Consequently, urban areas with insufficient functions can be identified, and resources can be accurately allocated to these areas for function enhancement. Second, this study has developed a framework for UC identification based on POI data. Thus, changes in UC distribution can be captured in real time, providing a baseline for testing the effectiveness of urban decentralization policies.

\section{Conclusions}

\subsection{Key Findings}

UC identification plays an important role in the research field of USS analyses. This study established a framework for identifying UCs from the perspective of urban functions. In this framework, POI data were utilized to identify UCs based on the DBSCAN algorithm. The distribution of the identified UCs was then validated by CVNN and visualized on ArcGIS.

Beijing was selected as an exemplary case to display the application of this framework. Five urban functions were investigated-residence, education, catering, shopping, and leisure and recreation. The results showed that Beijing is experiencing a decentralization of urban functions, which has driven the city's transformation from monocentric to polycentric; however, this decentralization is relatively low with uneven distribution of UCs. Generally, the distributions of catering and shopping UCs display significantly polycentric features. To facilitate Beijing's transition to a polycentric city, local governments should focus on decentralizing the other three types of urban functions-residence, education, and leisure and recreation. Strategies like constructing super-large communities, developing branch campuses and higher-education parks, and enhancing modern cultural industries should be adopted in the 11 new towns.

\subsection{Limitations}

A few limitations should be acknowledged. First, because the DBSCAN algorithm is an unsupervised clustering method, its effectiveness relies on the structure and quality of the data. POI data collected from different sources may generate different results in terms of UC identification. 
Thus, the robustness of the UC identification framework should be further tested. Second, this study focused on UC identification but failed to explore interactions among different UCs. In practice, UCs with diverse functions can interact with each other, which in turn can significantly affect the overall functions of a city. Therefore, future studies should be conducted to investigate UCs in light of their interactions.

Author Contributions: Conceptualization, L.Y. and T.Y.; methodology, L.Y. and Y.W.; validation, Y.W. and G.W.; writing - original draft preparation, L.Y. and T.Y.; writing-review and editing, L.Y. and T.Y.; supervision, T.Y. and Y.W. All authors have read and agreed to the published version of the manuscript.

Funding: This research was funded by the National Natural Science Foundation of China (No. 71901082) and the China Postdoctoral Science Foundation (No. 2019M651295).

Acknowledgments: The authors thank the editors and anonymous reviewers for their valuable and constructive suggestions for improving this paper.

Conflicts of Interest: The authors declare no conflict of interest.

\section{References}

1. Tan, Y.; Xu, H.; Zhang, X. Sustainable urbanization in China: A comprehensive literature review. Cities 2016, 55, 82-93. [CrossRef]

2. National Bureau of Statistics of China. China Statistical Yearbook-2019; China Statistical Press: Beijing, China, 2019.

3. Huang, J.; Levinson, D.; Wang, J.; Jin, H. Job-worker spatial dynamics in Beijing: Insights from Smart Card Data. Cities 2019, 86, 83-93. [CrossRef]

4. Huang, D.; Liu, Z.; Zhao, X. Monocentric or Polycentric? The Urban Spatial Structure of Employment in Beijing. Sustainability 2015, 7, 11632-11656. [CrossRef]

5. Ren, X. Urban China; John Wiley \& Sons: Hoboken, NJ, USA, 2013.

6. Li, J.; Long, Y.; Dang, A. Live-Work-Play Centers of Chinese cities: Identification and temporal evolution with emerging data. Comput. Environ. Urban Syst. 2018, 71, 58-66. [CrossRef]

7. Sun, Y.; Fan, H.; Li, M.; Zipf, A. Identifying the city center using human travel flows generated from location-based social networking data. Environ. Plan. B Plan. Des. 2016, 43, 480-498. [CrossRef]

8. Tian, G.; Wu, J.; Yang, Z. Spatial pattern of urban functions in the Beijing metropolitan region. Habitat Int. 2010, 34, 249-255. [CrossRef]

9. Burger, M.; Meijers, E. Form Follows Function? Linking Morphological and Functional Polycentricity. Urban Stud. 2012, 49, 1127-1149. [CrossRef]

10. Huang, D.; Liu, Z.; Zhao, X.; Zhao, P. Emerging polycentric megacity in China: An examination of employment subcenters and their influence on population distribution in Beijing. Cities 2017, 69, 36-45. [CrossRef]

11. Veneri, P. The identification of sub-centres in two Italian metropolitan areas: A functional approach. Cities 2013, 31, 177-185. [CrossRef]

12. Cai, J.; Huang, B.; Song, Y. Using multi-source geospatial big data to identify the structure of polycentric cities. Remote Sens. Environ. 2017, 202, 210-221. [CrossRef]

13. United Nations. 2018 Revision of the World Urbanization Prospects; United Nations: New York, NY, USA, 2018.

14. Clark, W.A.V. Monocentric to polycentric: New urban forms and old paradigms. In A Companion to the City; Bridge, G., Watson, S., Eds.; Wiley-Blackwell: Malden, MA, USA, 2000; pp. 141-154.

15. Craig, S.G.; Ng, P.T. Using Quantile Smoothing Splines to Identify Employment Subcenters in a Multicentric Urban Area. J. Urban Econ. 2001, 49, 100-120. [CrossRef]

16. McDonald, J.F.; Prather, P.J. Suburban Employment Centres: The Case of Chicago. Urban Stud. 1994, 31, 201-218. [CrossRef]

17. McMillen, D.P. Nonparametric Employment Subcenter Identification. J. Urban Econ. 2001, 50, 448-473. [CrossRef]

18. McMillen, D.P.; McDonald, J.F. A Nonparametric Analysis of Employment Density in a Polycentric City. J. Reg. Sci. 1997, 37, 591-612. [CrossRef] 
19. Qin, B.; Han, S.S. Emerging Polycentricity in Beijing: Evidence from Housing Price Variations, 2001-05. Urban Stud. 2013, 50, 2006-2023. [CrossRef]

20. Wen, H.; Tao, Y. Polycentric urban structure and housing price in the transitional China: Evidence from Hangzhou. Habitat Int. 2015, 46, 138-146. [CrossRef]

21. Zou, Y.; Mason, R.; Zhong, R. Modeling the polycentric evolution of post-Olympic Beijing: An empirical analysis of land prices and development intensity. Urban Geogr. 2015, 36, 735-756. [CrossRef]

22. Feng, J.; Wang, F.; Zhou, Y. The Spatial Restructuring of Population in Metropolitan Beijing: Toward Polycentricity in the Post-Reform ERA. Urban Geogr. 2009, 30, 779-802. [CrossRef]

23. Liu, X.; Wang, M. How polycentric is urban China and why? A case study of 318 cities. Landsc. Urban Plan. 2016, 151, 10-20. [CrossRef]

24. Zhong, C.; Schläpfer, M.; Müller Arisona, S.; Batty, M.; Ratti, C.; Schmitt, G. Revealing centrality in the spatial structure of cities from human activity patterns. Urban Stud. 2017, 54, 437-455. [CrossRef]

25. McDonald, J.F. The identification of urban employment subcenters. J. Urban Econ. 1987, 21, $242-258$. [CrossRef]

26. Giuliano, G.; Small, K.A. Subcenters in the Los Angeles region. Reg. Sci. Urban Econ. 1991, 21, $163-182$. [CrossRef]

27. Giuliano, G.; Redfearn, C.; Agarwal, A.; Li, C.; Zhuang, D. Employment Concentrations in Los Angeles, 1980-2000. Environ. Plan. A Econ. Space 2007, 39, 2935-2957. [CrossRef]

28. Leslie, T.F. Identification and Differentiation of Urban Centers in Phoenix Through a Multi-Criteria Kernel-Density Approach. Int. Reg. Sci. Rev. 2010, 33, 205-235. [CrossRef]

29. Zhong, C.; Huang, X.; Arisona, S.M.; Schmitt, G. Identifying Spatial Structure of Urban Functional Centers Using Travel Survey Data: A Case Study of Singapore. In Proceedings of the First ACM SIGSPATIAL International Workshop on Computational Models of Place, Orlando, FL, USA, 5-8 November 2013; pp. $28-33$.

30. Hu, Y.; Gao, S.; Janowicz, K.; Yu, B.; Li, W.; Prasad, S. Extracting and understanding urban areas of interest using geotagged photos. Comput. Environ. Urban Syst. 2015, 54, 240-254. [CrossRef]

31. Yuan, J.; Zheng, Y.; Xie, X. Discovering regions of different functions in a city using human mobility and POIs. In Proceedings of the 18th ACM SIGKDD international conference on Knowledge discovery and data mining, Beijing, China, 12-16 August; pp. 186-194.

32. Gao, S.; Janowicz, K.; Couclelis, H. Extracting urban functional regions from points of interest and human activities on location-based social networks. Trans. Gis 2017, 21, 446-467. [CrossRef]

33. Yao, Y.; Li, X.; Liu, X.; Liu, P.; Liang, Z.; Zhang, J.; Mai, K. Sensing spatial distribution of urban land use by integrating points-of-interest and Google Word2Vec model. Int. J. Geogr. Inf. Sci. 2017, 31, 825-848. [CrossRef]

34. Zhai, W.; Bai, X.; Shi, Y.; Han, Y.; Peng, Z.-R.; Gu, C. Beyond Word2vec: An approach for urban functional region extraction and identification by combining Place2vec and POIs. Comput. Environ. Urban Syst. 2019, 74, 1-12. [CrossRef]

35. Long, Y.; Shen, Z. Discovering Functional Zones Using Bus Smart Card Data and Points of Interest in Beijing. Geospat. Anal. Support Urban Plan. Beijing 2015, 10, 193-217.

36. Zhou, X.; Zhang, L. Crowdsourcing functions of the living city from Twitter and Foursquare data. Cartogr. Geogr. Inf. Sci. 2016, 43, 393-404. [CrossRef]

37. Jiang, S.; Alves, A.; Rodrigues, F.; Ferreira, J.; Pereira, F.C. Mining point-of-interest data from social networks for urban land use classification and disaggregation. Comput. Environ. Urban Syst. 2015, 53, 36-46. [CrossRef]

38. Zhi, Y.; Li, H.; Wang, D.; Deng, M.; Wang, S.; Gao, J.; Duan, Z.; Liu, Y. Latent spatio-temporal activity structures: A new approach to inferring intra-urban functional regions via social media check-in data. Geo-Spat. Inf. Sci. 2016, 19, 94-105. [CrossRef]

39. Liu, X.; Long, Y. Automated identification and characterization of parcels with OpenStreetMap and points of interest. Environ. Plan. B Plan. Des. 2016, 43, 341-360. [CrossRef]

40. Halkidi, M.; Batistakis, Y.; Vazirgiannis, M. On Clustering Validation Techniques. J. Intell. Inf. Syst. 2001, 17, 107-145. [CrossRef]

41. Liu, P.; Zhou, D.; Wu, N. VDBSCAN: Varied Density Based Spatial Clustering of Applications with Noise. In Proceedings of the 2007 International Conference on Service Systems and Service Management, Chengdu, China, 9-11 June 2007; pp. 1-4. 
42. Parimala, M.; Lopez, D.; Senthilkumar, N.C. A Survey on Density Based Clustering Algorithms for Mining Large Spatial Databases. Int. J. Adv. Sci. Technol. 2011, 31, 59-66.

43. Khan, K.; Rehman, S.U.; Aziz, K.; Fong, S.; Sarasvady, S. DBSCAN: Past, present and future. In Proceedings of the Fifth International Conference on the Applications of Digital Information and Web Technologies (ICADIWT 2014), Bangalore, India, 17-19 February 2014; pp. 232-238.

44. Gaonkar, M.N.; Sawant, K. AutoEpsDBSCAN: DBSCAN with Eps Automatic for Large Dataset. Int. J. Adv. Comput. Theory Eng. 2013, 2, 11-16.

45. Starczewski, A.; Cader, A. Determining the Eps Parameter of the DBSCAN Algorithm. In Proceedings of the International Conference on Artificial Intelligence and Soft Computing (ICAISC 2019), Zakopane, Poland, 16-20 June 2019; pp. 420-430.

46. Zhou, H.; Wang, P.; Li, H. Research on Adaptive Parameters Determination in DBSCAN Algorithm. J. Inf. Comput. Sci. 2012, 9, 1967-1973.

47. Ester, M.; Kriegel, H.P.; Sander, J.; Xu, X. A Density-Based Algorithm for Discovering Clusters in Large Spatial Databases with Noise. In Proceedings of the International Conference on Knowledge Discovery \& Data Mining (KDD-96), Oregon, Portland, 2-4 August 1996; pp. 226-231.

48. Karami, A.; Johansson, R. Choosing DBSCAN Parameters Automatically using Differential Evolution. Int. J. Comput. Appl. 2014, 91,1-11. [CrossRef]

49. Maulik, U.; Bandyopadhyay, S. Performance evaluation of some clustering algorithms and validity indices. IEEE Trans. Pattern Anal. Mach. Intell. 2002, 24, 1650-1654. [CrossRef]

50. Liu, Y.; Li, Z.; Xiong, H.; Gao, X.; Wu, J. Understanding of Internal Clustering Validation Measures. In Proceedings of the 2010 IEEE International Conference on Data Mining, Sydney, Australia, 14-17 December 2010; pp. 911-916.

51. Liu, Y.; Li, Z.; Xiong, H.; Gao, X.; Wu, J.; Wu, S. Understanding and enhancement of internal clustering validation measures. IEEE Trans. Cybern. 2013, 43, 982-994. [CrossRef]

52. Beijing Statistics Bureau. Beijing Statistics Yearbook in 2018; Chinese Statistics Press: Beijing, China, 2018.

53. Beijing Municipal Commission of Planning and Natural Resources. The 2016-2035 Urban Master Plan of Beijing; Resources, B.M., Ed.; Beijing Municipal Commission of Planning and Natural Resources: Beijing, China, 2018.

54. Sina Education. New Campus Opened in Suburbs of Several Universities in Beijing. Available online: http://edu.sina.com.cn/ (accessed on 26 March 2019).

55. Zheng, S.; Kahn, M.E. Land and residential property markets in a booming economy: New evidence from Beijing. J. Urban Econ. 2008, 63, 743-757. [CrossRef] 